\title{
Dizziness and Imbalance in the Elderly: Age-related Decline in the Vestibular System
}

\author{
Shinichi Iwasaki*, Tatsuya Yamasoba \\ Department of Otolaryngology, Faculty of Medicine, University of Tokyo, Tokyo, Japan
}

[Received November 19, 2013; Revised January 27, 2014; Accepted January 28, 2014]

\begin{abstract}
Dizziness and imbalance are amongst the most common complaints in older people, and are a growing public health concern since they put older people at a significantly higher risk of falling. Although the causes of dizziness in older people are multifactorial, peripheral vestibular dysfunction is one of the most frequent causes. Benign paroxysmal positional vertigo is the most frequent form of vestibular dysfunction in the elderly, followed by Meniere's disease. Every factor associated with the maintenance of postural stability deteriorates during aging. Age-related deterioration of peripheral vestibular function has been demonstrated through quantitative measurements of the vestibulo-ocular reflex with rotational testing and of the vestibulo-collic reflex with testing of vestibular evoked myogenic potentials. Age-related decline of vestibular function has been shown to correlate with the age-related decrease in the number of vestibular hair cells and neurons. The mechanism of age-related cellular loss in the vestibular endorgan is unclear, but it is thought that genetic predisposition and cumulative effect of oxidative stress may both play an important role. Since the causes of dizziness in older people are multi-factorial, management of this disease should be customized according to the etiologies of each individual. Vestibular rehabilitation is found to be effective in treating both unilateral and bilateral vestibular dysfunction. Various prosthetic devices have also been developed to improve postural balance in older people. Although there have been no medical treatments improving age-related vestibular dysfunction, new medical treatments such as mitochondrial antioxidants or caloric restriction, which have been effective in preventing age-related hearing loss, should be ienvestigated in the future.
\end{abstract}

Key words: aging, vestibular, fall, rehabilitation.

Dizziness and imbalance are well-recognized problems among older people. A population-based study in the United States reported that $24 \%$ of people older than 72 years have dizziness [1]. Dizziness and imbalance in older people are a growing public health concern, because older individuals who suffer from dizziness have a significantly higher risk of accidental falls and consequent injuries $[2,3]$. Falls are the leading cause of hospital admission and accidental death in older people. Several studies have shown that older adults with a history of dizziness and imbalance are at a higher risk of falling [3-5]. Furthermore, vertigo and unsteadiness lead to a fear of falling, which is a strong predictor for those who will suffer one or more subsequent falls [6,7].

The underlying cause of dizziness in the elderly is complex and multi-factorial $[8,9]$. Postural stability is maintained by the integration of somatosensory, visual and vestibular inputs to the central nervous system, followed by outputs to the musculo-skeletal system (Fig. 1). Dizziness and imbalance can be caused by changes in any of the factors associated the balance system, be they of sensory, visual, vestibular, neurologic, and muscular origin. Function of all these components deteriorates with age [10].

*Correspondence should be addressed to: Shinichi Iwasaki, MD. Department of Otolaryngology, Faculty of Medicine, University of Tokyo, 7-3-1 Hongo, Bunkyo-ku, Tokyo 113-8655, Japan. E-mail: iwashin-tky@umin.ac.jp 


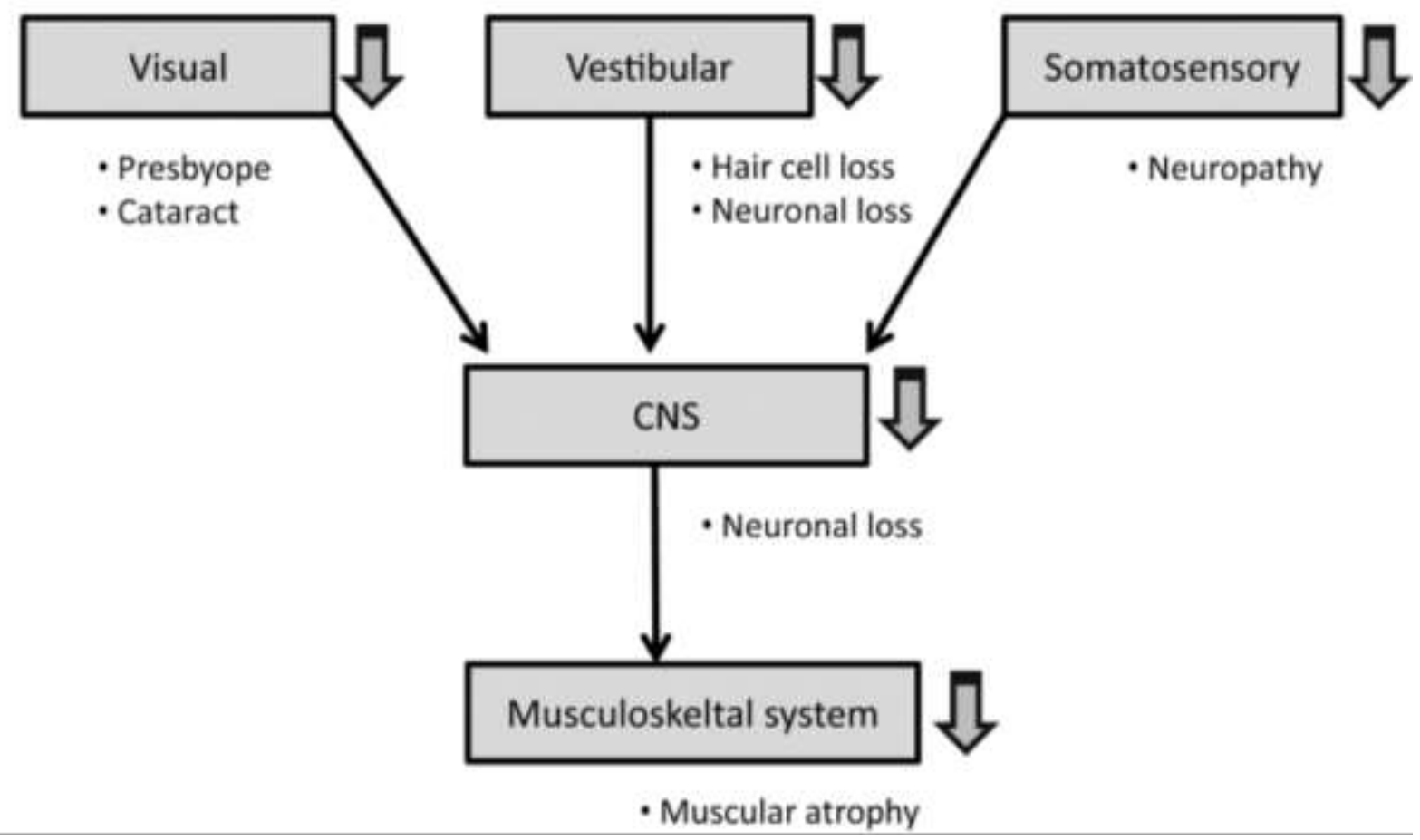

Figure 1. Age-dependent changes in the system maintaining postural stability. Postural stability is maintained by the integration of somatosensory, visual and vestibular inputs to the central nervous system, followed by outputs to the musculoskeltal system. Function of all the components deteriorates as the age advances.

This review will focus on the clinical characteristics of dizziness in the elderly and age-related changes in the peripheral and central vestibular systems, and will report some recent findings on cellular mechanism of aging and the possible treatment strategies for dealing with dizziness and imbalance in the elderly.

\section{Prevalence of dizziness and imbalance in the elderly}

Dizziness and imbalance are one of the most common complaints among older people. The prevalence ranges from approximately $20 \%$ to $30 \%$, depending on the definition of dizziness and the population studied $[1,11,12]$. A population-based study in the United States found that $24 \%$ of people older than 72 years reported having an episode of dizziness within the previous 2 months, lasting for at least one month [1]. Another population-based study in the United Kingdom reported that $30 \%$ of people older than 65 years have dizziness [11]. The prevalence of dizziness has a tendency to increase with age [1,11]. A cross-sectional study in Sweden reported that the number of adults with dizziness increased up to approximately $50 \%$ in people older than 85 [13].

The underlying causes of dizziness in the elderly vary widely [1,8,14-17]. Multiple factors including neurologic, cardiovascular, visual, vestibular, and psychological problems can cause dizziness in older people. Previous studies have reported conflicting results regarding the etiologies of dizziness depending on the diagnostic criteria adopted and the population studied. General population studies have usually assigned the causes of dizziness mainly on the basis of interview without performing any clinical examinations. A population survey in Germany reported that a prevalence of vestibular vertigo was $14 \%$ in the general population older than 70 years [14]. Their diagnoses were based on telephone interviews by medical staff. Studies in clinical settings were biased by the types of clinics and physical examinations performed. A prospective case control study conducted in general practices, in which general physical examinations were performed, reported $18 \%$ of patients with dizziness who were over 60 years old had a peripheral vestibular disorder [8]. On the other hand, a 
prospective study in a neurology clinic, in which detailed neuro-otological examinations were performed, reported that peripheral vestibular dysfunction was the principal cause of dizziness in $56 \%$ of patients older than 50 years [15]. Similarly, cerebrovascular causes range from $0 \%$ to $70 \%[8,18]$, and psychiatric causes in $0 \%$ to $40 \%$ in older patients with dizziness $[8,15,19]$ depending on the clinical examination performed. In several studies, no specific diagnosis could be made to explain the symptoms in approximately $20 \%$ to $30 \%$ of older people with dizziness $[8,9,17]$. Belal and Glorig (1986) used the term presbystasis to describe this type of age-related problem that cannot be attributed to any known diagnosis [17]. On the other hand, other studies assigned multiple diagnoses in $18 \%$ to $85 \%$ of older people with dizziness $[8,15,18]$. Tinetti et al. (2000) proposed that dizziness in the elderly should be considered as a multifactorial geriatric syndrome involving many different symptoms and originating from many different causes, including cardiovascular, neurologic, sensory, psychological and medication-related problems [1].

\section{Peripheral vestibular disorders in the elderly}

In most studies regarding dizziness in the elderly, peripheral vestibular dysfunction is the first or the second most frequent cause of dizziness $[8,9,15,20]$. Benign paroxysmal positional vertigo (BPPV) is the most frequent form of peripheral vestibular dysfunction, followed by Meniere's disease and vestibular neuritis $[9,15]$.

BPPV is the most common cause of vertigo and dizziness from childhood through to old age, peaking at about 60 years [21]. Several studies have demonstrated an increase in incidence of BPPV in older people $[20,22,23]$. A recent epidemiologic study obtained from a large crosssectional neurotologic survey reported that lifetime prevalence of BPPV was estimated to be $2.4 \%$ and the one year prevalence of $1.6 \%$ but that one-year prevalence of BPPV in adults older than 60 years was approximately seven times higher than that of adults from 18 to 39 years old [22]. BPPV is usually diagnosed by the presence of episodic vertigo provoked by changes in head position and concomitant nystagmus observed during the positioning maneuver [24,25]; it is effectively treated by physical therapy [26-28]. Johkura et al. (2008) reported that about $50 \%$ of elderly patients with chronic dizziness who visited an emergency unit showed extremely weak, horizontal, direction changing apogeotropic nystagmus, which is characteristic of horizontal canal BPPV, and that some of symptoms in these patients was improved by daily positional exercises for BPPV [29]. The results suggest that the reported prevalence of BPPV in older people might be underestimated.

The cause of BPPV is thought to be small particles trapped in the semicircular canals [25,30]. These particles most likely consist of otoconia dislodged from the utricula maculae. Several studies have demonstrated that a high proportion of otoconia of the utricular macula degenerates in the elderly, and many have fractures [31,32]. Morphological changes in the otolith organs may be related to the increased prevalence of BPPV in the older people.

Meniere's disease accounts for 3\% to $11 \%$ of diagnosed dizziness in neuro-otological clinics. Its annual incidence rate and point prevalence are estimated to be $15 / 100,000$ and 218/100,000, respectively, in the general population [33]. Meniere's disease has generally been regarded as a disease of middle-aged people [34,35]. However, in a large case series study, Ballester et al. (2002) reported that $15 \%$ of patients with Meniere's disease are more than 65 years of age [34]. In that study, $40 \%$ of cases were a reactivation of longstanding Meniere's disease while $60 \%$ were de novo case of Meniere's disease. They also reported that drop attacks, which are caused by sudden otolithic dysfunction, were more frequent in older people compared to the general population. A multi-center survey in Japan reported the proportion of de novo cases of Meniere's disease in patients older than 60 years had increased during the previous 30 years [36] .

Vestibular neuritis accounts for $3 \%$ to $10 \%$ of diagnoses in oto-neurological clinics [20,37]. The epidemiological data on vestibular neuritis is scarce. An epidemiological survey in Japan reported that the prevalence of vestibular neuritis is $3.5 / 100,000$ and the peak age distribution was between 40 to 50 years [38]. Although vestibular compensation relieves most of the symptoms of vestibular neuritis within a few weeks of onset, $30 \%$ to $40 \%$ of patients have chronic persistent dizziness [39-41]. Furthermore, deterioration in function of the intact side of the peripheral vestibular organs, vision, and the proprioceptive systems in the elderly may lead to a breakdown of vestibular compensation.

\section{Functional deterioration of vestibular systems in the elderly}

The stability of posture and gaze during standing and walking is maintained by the rapid processing of vestibular, visual and somatosensory inputs in the central nervous systems, followed by outputs to the musculoskeletal and visual systems. Every factor in this system deteriorates during aging. 

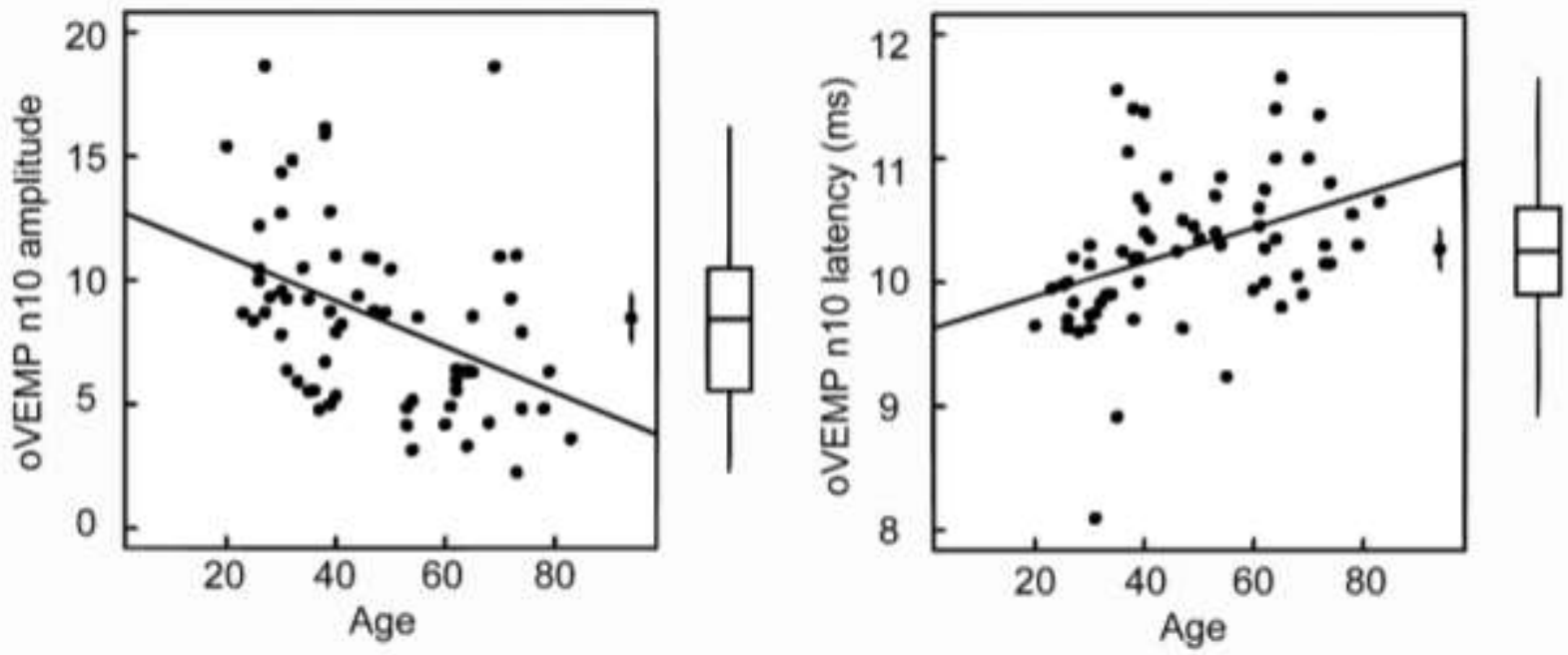

Figure 2. Age-dependent changes in amplitude and latency of oVEMPs to bone-conducted vibration. (Left panel) Amplitude of the n10 responses of oVEMP significantly decreases with age. (Right panel) Latency of the $n 10$ responses of oVEMP significantly increases with age. The box and whisker plots show the median and quartiles (cited from ref. 54 with permission).

Age-related deterioration of peripheral vestibular function has been documented by measuring the vestibulo-ocular reflex (VOR) using rotational tests and/or caloric tests, both of which reflect function of the lateral semicircular canals [42-44]. Sinusoidal rotation tests in normal adults over the age of 75 years showed a decrease in VOR gain as well as the VOR time constant, especially with high velocity stimulation, as compared with young subjects [42]. In a longitudinal study of normal subjects older than 75 years old, a progressive decrease in VOR gain and an increase in phase lead were observed during five annual examinations [45]. Another study assessing performance in sinusoidal rotational tests and caloric tests in normal subjects from 7 to 81 years old reported a decline in the response amplitude and less of a compensatory response phase with increasing age in the rotational test, while the caloric test showed no consistent trends with age [44]. These results suggest that age-related changes in vestibular system preferentially affect the high-frequency component of the VOR since the caloric testing reflects the low frequency component of the VOR.

Age-related deterioration of peripheral vestibular function has been demonstrated in other vestibular tests. Vestibular evoked myogenic potentials (VEMPs) are short-latency muscle responses typically recorded from the neck muscles (cVEMPs) or from the eye muscles (oVEMPs) [46-48]. Clinical and physiological studies have shown that cVEMPs reflect the function of the saccule and the inferior vestibular nerve whereas oVEMPs reflects the function of the utricle and the superior vestibular nerve [49-52]. A cross sectional study of consecutive patients ranging from 7 to 91 years old showed an age-dependent decrease in cVEMP amplitude and an increase in cVEMP latency [53]. Similarly, oVEMPs show an age-dependent decrease in amplitude and an increase in latency (Fig.2) [54]. These results suggest that the function of the otolith organs as well as their central pathway also deteriorate with increasing age. Recently, Agrawal et al. (2012) measured the function of the semicircular canals, utricle, and saccule using the head thrust test, oVEMP, and cVEMP, respectively, in healthy subjects more than 70 years old [55]. They showed that the function of the semicircular canals as well as the otolith organs decline with age, although the magnitude of impairment was greater for the semicircular canals than the otolith organs. However, deterioration of the results of the head thrust test might reflect an element of deterioration of oculomotor function as well as the semicircular canal function.

Age-related changes in postural stability have been examined using posturography, in which changes of the center of pressure was measured during quiet standing [56-59]. For estimating the role of different sensory inputs on postural control, dynamic posturography using a moving platform or a foam rubber surface have also been developed. In most studies, all measures of balance 
performance get worse in older subjects compared with younger subjects (Fig. 3) [57-59]. This age-related decline in balance control is correlated with deterioration of visual, vestibular, and sensorimotor function as well as reduction in strength of the lower muscles. Teasdale et al. (1991) have demonstrated that alteration in any two of the three sensory inputs (visual, vestibular and somatosensory) had a significantly greater effect on older subjects than in younger subjects whereas alteration in one input did not have a significant effect due to age [59]. These results suggest that decreased inputs from the vestibular, visual and somatosensory systems in older subjects lead to a decreased capacity for compensation by the other inputs in order to maintain postural stability.
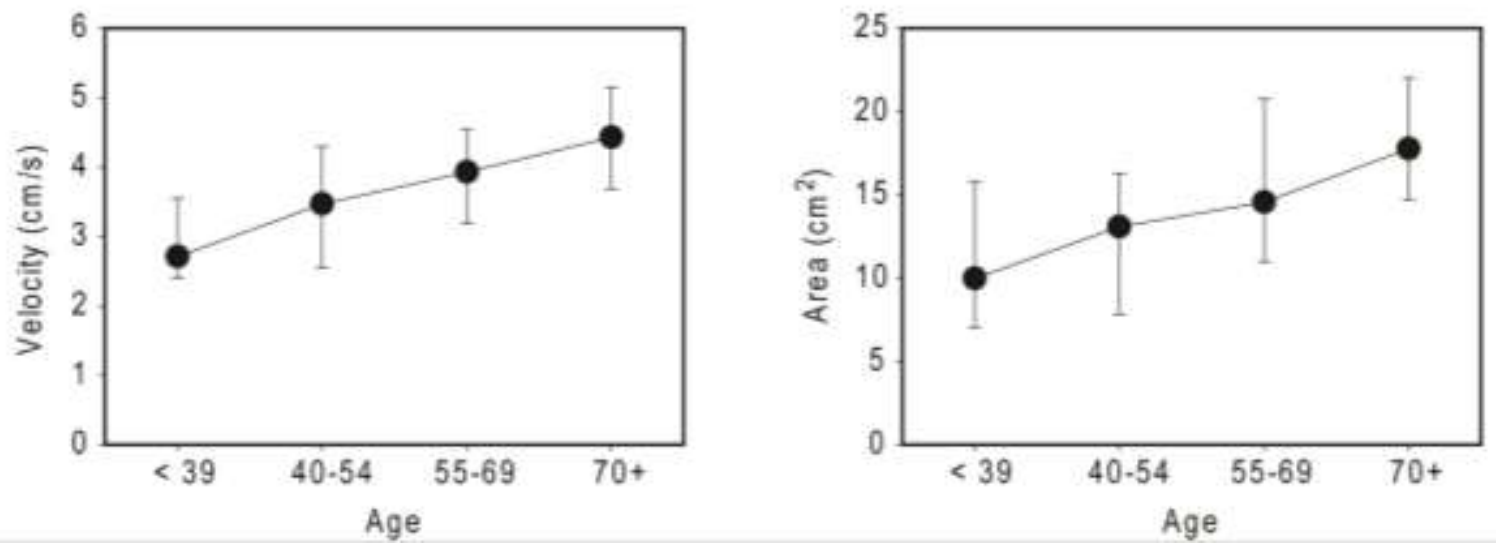

Figure 3. Age-dependent changes in the postural stability on the foam rubber. (Left panel) Age-dependent changes in the velocity of the center of pressure (COP) during standing with eyes closed on the foam rubber. (Right panel) Age-dependent changes in the envelopment area of the COP during standing with eyes closed on the foam rubber. Median value and interquatile ranges are shown (The data are from ref. 57).

\section{Cellular changes in aging of the vestibular system}

Hair cells and neurons in the vestibular system do not regenerate or increase basically in the mammals. A significant decrease in the number of hair cells and neurons in the vestibular system in older people has been described in the literature [60,61]. Richter (1980) examined the density of vestibular hair cells and nerve cells in Scarpa's ganglia in human temporal bones from subjects aged 9 to 91 years old [60]. He reported a decrease in the number of vestibular hair cells after the age of 20 years old and a decrease in the number of vestibular ganglion neurons after the age of 50 years. On the other hand, Merchant et al. (2000) reported a gradual loss in the number of vestibular hair cells in all endrogans, with relative sparing of the utricle, with increasing age [62]. These early reports, which estimated the number of vestibular hair cells and neurons from serial sections of the temporal bones, may have been biased as they were based on several assumptions such as the spherical shape and uniform size of the hair cells as well as the constant shrinkage and thickness of the specimen. Recently, using unbiased stereology which overcomes the shortcomings of previous methods, the number of hair cells and neurons in human temporal bones was re-evaluated $[63,64]$. Lopez et al. (2005) examined the number of hair cells in the semicircular canals using unbiased stereology and showed that the number of hair cells was decreased by $12 \%$ in adults in their $80 \mathrm{~s}$ and by $25 \%$ in their $90 \mathrm{~s}$ as compared with the younger group (42 to 67 years old) [63]. Gopen et al. (2003) used the same method to estimate the number of hair cells in the utricle but they failed to show an agedependent decrease in the number of hair cells [64]. It remains unclear whether this result reflects the relative sparing of the utricle in age-related loss of hair cells [62], or is due to bias caused by the paucity of the number of temporal bones examined.

In contrast to numerous reports regarding animal models of age-related hearing loss, animal models of agerelated vestibular dysfunction have rarely been reported. 
Shiga et al. (2005) examined age-related changes of vestibular endorgans in C57BL/6 mice, which are considered to be an animal model of age-related hearing loss, and reported an age-related decline in hair cell density in the horizontal semicircular canals of $30 \%$, with an associated mild decrease in the VOR gain at $0.8 \mathrm{~Hz}$ [65]. Since the age-related decrease of VOR gain was not observed at the other frequencies tested, it was speculated that a differential loss of hair cell types might occur in the model mice.

The mechanism of age-related cellular loss in the vestibular endorgans is still unclear. However, the possible etiology of age-related hearing loss has been extensively studied [66-68], and it is now considered to be a multifactorial condition, representing outocome of multiple intrinsic (e.g. genetic predisposition) and extrinsic (e.g. noise exposure) factors acting on the inner ear over a life time [66]. A number of studies using animal models have suggested that the cumulative effect of oxidative stress could induce damage to macromolecules such as mitochondrial DNA and that the accumulation of mitochondrial DNA and the decline of mitochondrial function play an important role in inducing apoptosis of the cochlear cells [69-71]. Genetic investigations have shown that several genes, including those related to antioxidant defense and atherosclerosis, have an association with age-related hearing loss [72]. Exposure to noise is known to induce excess generation of reactive oxygen species in the cochlea [73]. A similar accumulation of oxidative stress and damage to mitochondrial DNA may be taking place in age-related changes in the vestibular endorgans.

\section{Management of dizziness in the elderly}

Since the causes of dizziness in older people are multifactorial, management of this disease should be customized according to the etiology of dizziness in each individual. Management of dizziness includes various approaches, including medical and rehabilitative ones as well as the use of prosthetic devices.

Vestibular rehabilitation was first introduced by Cawthorne and Cooksey (1946) to rehabilitate patients with vestibular disorders [74]. The rehabilitation includes 1) VOR adaptation exercises to assist the central nervous system to adapt to a change or loss in inputs to the vestibular system, 2) habituation exercises to reduce pathologic responses to a provoking stimulus, and 3) substitution exercises to promote the use of the remaining sensory system [75]. Currently, these exercises are found to be effective in treating people with dizziness caused by vestibular dysfunction, anxiety, head injury, cerebellar dysfunction, or Parkinson's disease [76]. The effect of vestibular rehabilitation does not differ with respect to patients' age and gender [77]. Several randomized control studies have provided evidence that vestibular rehabilitation exercises are effective in improving postural control, reports of dizziness symptoms, and emotional status in dizzy patients with nonspecific causes $[75,78,79]$.

Various prosthetic devices have been developed to improve postural balance in the elderly. Vibrotactile feedback devices, which fit around the waist and provide augmented feedback about body tilt thorough vibration, have been shown to improve postural balance during quiet standing and walking [80,81]. A tongue-placed biofeedback system which provides information about head position by electrotactile stimulation was also reported to improve head stability in space [82]. Vibrating insoles which enhance somatosensory input from the lower extremities have been reported to improve postural performance in the elderly [83].

So far, there are no medical treatments to improve age-related deterioration of vestibular function. However, several medications have been reported to be effective in preventing age-related changes in the inner ear. Oral supplementation with mitochondrial antioxidants such as alpha-lipoic acid and coenzyme Q10 has been shown to reduce age-dependent hair cell loss in the mouse inner ear [71]. Caloric restriction extends the lifespan of most mammalian species by down-regulation of the expression of apoptotic genes. It has been reported to be effective for preventing age-related hearing loss in animal studies [84]. These new treatments which have been effective in animal studies should be applied in older patients with vestibular dysfunction in the future.

\section{Acknowledgement}

We thank Dr. Chisato Fujimoto for critically reading the manuscript. This study was supported by a grant from the Ministry of Education, Culture, Sports, Science and Technology (25293347).

\section{References}

[1] Tinetti ME, Williams CS, Gill TM (2000). Dizziness among older adults: a possible geriatric syndrome. Ann Intern Med, 132(5): 337-344.

[2] Graafmans WC, Ooms ME, Hofstee HM, Bezemer PD, Bouter LM, Lips P (1996). Falls in the elderly: a prospective study of risk factors and risk profiles. Am J Epidemiol, 143(11): 1129-1136.

[3] O'Loughlin JL, Boivin JF, Robitaille Y, Suissa S (1994). Falls among the elderly: distinguishing 
indoor and outdoor risk factors in Canada. J Epidemiol Community Health, 48(5): 488-489.

[4] Rubenstein LZ, Josephson KR (2006). Falls and their prevention in elderly people: what does the evidence show? Med Clin North Am, 90(5): 807824.

[5] Stel VS, Pluijm SM, Deeg DJ, Smit JH, Bouter LM, Lips P (2003). A classification tree for predicting recurrent falling in community-dwelling older persons. J Am Geriatr Soc, 51(10): 1356-1364.

[6] Delbaere K, Crombez G, Vanderstraeten G, Willems T, Cambier D (2004). Fear-related avoidance of activities, falls and physical frailty. A prospective community-based cohort study. Age Ageing, 33(4): 368-373.

[7] Li F, Fisher KJ, Harmer P, McAuley E, Wilson NL (2003). Fear of falling in elderly persons: association with falls, functional ability, and quality of life. J Gerontol B Psychol Sci Soc Sci, 58(5): P283-290.

[8] Lawson J, Fitzgerald J, Birchall J, Aldren CP, Kenny RA (1999). Diagnosis of geriatric patients with severe dizziness. J Am Geriatr Soc, 47(1): 1217.

[9] Katsarkas A (1994). Dizziness in aging: a retrospective study of 1194 cases. Otolaryngol Head Neck Surg, 110(3): 296-301.

[10] Barin K, Dodson EE (2011). Dizziness in the elderly. Otolaryngol Clin North Am, 44(2): 437454, $\mathrm{x}$.

[11] Colledge NR, Wilson JA, Macintyre CC, MacLennan WJ (1994). The prevalence and characteristics of dizziness in an elderly community. Age Ageing, 23(2): 117-120.

[12] Sloane PD, Coeytaux RR, Beck RS, Dallara J (2001). Dizziness: state of the science. Ann Intern Med, 134(9 Pt 2): 823-832.

[13] Jonsson R, Sixt E, Landahl S, Rosenhall U (2004). Prevalence of dizziness and vertigo in an urban elderly population. J Vestib Res, 14(1): 47-52.

[14] Neuhauser HK, von Brevern M, Radtke A, Lezius F, Feldmann M, Ziese T, Lempert T (2005). Epidemiology of vestibular vertigo: a neurotologic survey of the general population. Neurology, 65(6): 898-904.

[15] Davis LE (1994). Dizziness in elderly men. J Am Geriatr Soc, 42(11): 1184-1188.

[16] Kroenke K, Lucas CA, Rosenberg ML, Scherokman B, Herbers JE, Jr., Wehrle PA, Boggi JO (1992). Causes of persistent dizziness. A prospective study of 100 patients in ambulatory care. Ann Intern Med, 117(11): 898-904.
[17] Belal A, Jr., Glorig A (1986). Dysequilibrium of ageing (presbyastasis). J Laryngol Otol, 100(9): 1037-1041.

[18] Colledge NR, Barr-Hamilton RM, Lewis SJ, Sellar RJ, Wilson JA (1996). Evaluation of investigations to diagnose the cause of dizziness in elderly people: a community based controlled study. BMJ, 313(7060): 788-792.

[19] Sloane PD, Hartman M, Mitchell CM (1994). Psychological factors associated with chronic dizziness in patients aged 60 and older. J Am Geriatr Soc, 42(8): 847-852.

[20] Neuhauser H, Leopold M, von Brevern M, Arnold $\mathrm{G}$, Lempert $\mathrm{T}$ (2001). The interrelations of migraine, vertigo, and migrainous vertigo. Neurology, 56(4): 436-441.

[21] Baloh RW, Honrubia V, Jacobson K (1987). Benign positional vertigo: clinical and oculographic features in 240 cases. Neurology, 37(3): 371-378.

[22] von Brevern M, Radtke A, Lezius F, Feldmann M, Ziese T, Lempert T, Neuhauser H (2007). Epidemiology of benign paroxysmal positional vertigo: a population based study. J Neurol Neurosurg Psychiatry, 78(7): 710-715.

[23] Neuhauser HK (2007). Epidemiology of vertigo. Curr Opin Neurol, 20(1): 40-46.

[24] Dix MR, Hallpike CS (1952). The pathology symptomatology and diagnosis of certain common disorders of the vestibular system. Proc R Soc Med, 45(6): 341-354.

[25] Brandt T, Steddin S (1993). Current view of the mechanism of benign paroxysmal positioning vertigo: cupulolithiasis or canalolithiasis? J Vestib Res, 3(4): 373-382.

[26] Epley JM (1992). The canalith repositioning procedure: for treatment of benign paroxysmal positional vertigo. Otolaryngol Head Neck Surg, 107(3): 399-404.

[27] Iwasaki S, Chihara Y, Ushio M, Ochi A, Murofushi T, Yamasoba T (2011). Effect of the canalith repositioning procedure on subjective visual horizontal in patients with posterior canal benign paroxysmal positional vertigo. Acta Otolaryngol, 131(1): 41-45.

[28] Semont A, Freyss G, Vitte E (1988). Curing the BPPV with a liberatory maneuver. Adv Otorhinolaryngol, 42(290-293.

[29] Johkura K, Momoo T, Kuroiwa Y (2008). Positional nystagmus in patients with chronic dizziness. J Neurol Neurosurg Psychiatry, 79(12): 1324-1326. 
[30] Parnes LS, McClure JA (1992). Free-floating endolymph particles: a new operative finding during posterior semicircular canal occlusion. Laryngoscope, 102(9): 988-992.

[31] Igarashi M, Saito R, Mizukoshi K, Alford BR (1993). Otoconia in young and elderly persons: a temporal bone study. Acta Otolaryngol Suppl, 504(26-29.

[32] Johnsson LG, Hawkins JE, Jr. (1972). Vascular changes in the human inner ear associated with aging. Ann Otol Rhinol Laryngol, 81(3): 364-376.

[33] Wladislavosky-Waserman P, Facer GW, Mokri B, Kurland LT (1984). Meniere's disease: a 30-year epidemiologic and clinical study in Rochester, Mn, 1951-1980. Laryngoscope, 94(8): 1098-1102.

[34] Ballester M, Liard P, Vibert D, Hausler R (2002). Meniere's disease in the elderly. Otol Neurotol, 23(1): 73-78.

[35] Shojaku H, Watanabe Y, Fujisaka M, Tsubota M, Kobayashi K, Yasumura S, Mizukoshi K (2005). Epidemiologic characteristics of definite Meniere's disease in Japan. A long-term survey of Toyama and Niigata prefectures. ORL J Otorhinolaryngol Relat Spec, 67(5): 305-309.

[36] Shojaku H, Watanabe Y, Yagi T, Takahashi M, Takeda T, Ikezono T, Ito J, Kubo T, Suzuki M, Takumida M, Takeda N, Furuya N, Yamashita H (2009). Changes in the characteristics of definite Meniere's disease over time in Japan: a long-term survey by the Peripheral Vestibular Disorder Research Committee of Japan, formerly the Meniere's Disease Research Committee of Japan. Acta Otolaryngol, 129(2): 155-160.

[37] Guilemany JM, Martinez P, Prades E, Sanudo I, De Espana R, Cuchi A (2004). Clinical and epidemiological study of vertigo at an outpatient clinic. Acta Otolaryngol, 124(1): 49-52.

[38] Sekitani T, Imate Y, Noguchi T, Inokuma T (1993). Vestibular neuronitis: epidemiological survey by questionnaire in Japan. Acta Otolaryngol Suppl, 503(9-12.

[39] Godemann F, Siefert K, Hantschke-Bruggemann M, Neu P, Seidl R, Strohle A (2005). What accounts for vertigo one year after neuritis vestibularis - anxiety or a dysfunctional vestibular organ? J Psychiatr Res, 39(5): 529-534.

[40] Murofushi T, Iwasaki S, Ushio M (2006). Recovery of vestibular evoked myogenic potentials after a vertigo attack due to vestibular neuritis. Acta Otolaryngol, 126(4): 364-367.

[41] Okinaka Y, Sekitani T, Okazaki H, Miura M, Tahara T (1993). Progress of caloric response of vestibular neuronitis. Acta Otolaryngol Suppl, 503(18-22.

[42] Baloh RW, Jacobson KM, Socotch TM (1993). The effect of aging on visual-vestibuloocular responses. Exp Brain Res, 95(3): 509-516.

[43] Paige GD (1992). Senescence of human visualvestibular interactions. 1. Vestibulo-ocular reflex and adaptive plasticity with aging. J Vestib Res, 2(2): 133-151.

[44] Peterka RJ, Black FO, Schoenhoff MB (1990). Age-related changes in human vestibulo-ocular reflexes: sinusoidal rotation and caloric tests. J Vestib Res, 1(1): 49-59.

[45] Baloh RW, Enrietto J, Jacobson KM, Lin A (2001). Age-related changes in vestibular function: a longitudinal study. Ann N Y Acad Sci, 942(210219.

[46] Chihara Y, Iwasaki S, Ushio M, Murofushi T (2007). Vestibular-evoked extraocular potentials by air-conducted sound: another clinical test for vestibular function. Clin Neurophysiol, 118(12): 2745-2751.

[47] Iwasaki S, McGarvie LA, Halmagyi GM, Burgess AM, Kim J, Colebatch JG, Curthoys IS (2007). Head taps evoke a crossed vestibulo-ocular reflex. Neurology, 68(15): 1227-1229.

[48] Welgampola MS, Colebatch JG (2005). Characteristics and clinical applications of vestibular-evoked myogenic potentials. Neurology, 64(10): 1682-1688.

[49] Murofushi T, Curthoys IS, Topple AN, Colebatch JG, Halmagyi GM (1995). Responses of guinea pig primary vestibular neurons to clicks. Exp Brain Res, 103(1): 174-178.

[50] Kushiro K, Zakir M, Sato H, Ono S, Ogawa Y, Meng H, Zhang X, Uchino Y (2000). Saccular and utricular inputs to single vestibular neurons in cats. Exp Brain Res, 131(4): 406-415.

[51] Iwasaki S, Chihara Y, Smulders YE, Burgess AM, Halmagyi GM, Curthoys IS, Murofushi T (2009). The role of the superior vestibular nerve in generating ocular vestibular-evoked myogenic potentials to bone conducted vibration at Fz. Clin Neurophysiol, 120(3): 588-593.

[52] Curthoys IS, Iwasaki S, Chihara Y, Ushio M, McGarvie LA, Burgess AM (2011). The ocular vestibular-evoked myogenic potential to airconducted sound; probable superior vestibular nerve origin. Clin Neurophysiol, 122(3): 611-616.

[53] Brantberg K, Granath K, Schart N (2007). Agerelated changes in vestibular evoked myogenic potentials. Audiol Neurootol, 12(4): 247-253. 
[54] Iwasaki S, Smulders YE, Burgess AM, McGarvie LA, Macdougall HG, Halmagyi GM, Curthoys IS (2008). Ocular vestibular evoked myogenic potentials to bone conducted vibration of the midline forehead at $\mathrm{Fz}$ in healthy subjects. Clin Neurophysiol, 119(9): 2135-2147.

[55] Agrawal Y, Zuniga MG, Davalos-Bichara M, Schubert MC, Walston JD, Hughes J, Carey JP (2012). Decline in semicircular canal and otolith function with age. Otol Neurotol, 33(5): 832-839.

[56] Wolfson L, Whipple R, Derby CA, Amerman P, Murphy T, Tobin JN, Nashner L (1992). A dynamic posturography study of balance in healthy elderly. Neurology, 42(11): 2069-2075.

[57] Baloh RW, Spain S, Socotch TM, Jacobson KM, Bell T (1995). Posturography and balance problems in older people. J Am Geriatr Soc, 43(6): 638-644.

[58] Fujimoto C, Murofushi T, Chihara Y, Ushio M, Sugasawa K, Yamaguchi T, Yamasoba T, Iwasaki S (2009). Assessment of diagnostic accuracy of foam posturography for peripheral vestibular disorders: analysis of parameters related to visual and somatosensory dependence. Clin Neurophysiol, 120(7): 1408-1414.

[59] Teasdale N, Stelmach GE, Breunig A (1991). Postural sway characteristics of the elderly under normal and altered visual and support surface conditions. J Gerontol, 46(6): B238-244.

[60] Richter E (1980). Quantitative study of human Scarpa's ganglion and vestibular sensory epithelia. Acta Otolaryngol, 90(3-4): 199-208.

[61] Rauch SD, Velazquez-Villasenor L, Dimitri PS, Merchant SN (2001). Decreasing hair cell counts in aging humans. Ann N Y Acad Sci, 942(220-227.

[62] Merchant SN, Velazquez-Villasenor L, Tsuji K, Glynn RJ, Wall C, 3rd, Rauch SD (2000). Temporal bone studies of the human peripheral vestibular system. Normative vestibular hair cell data. Ann Otol Rhinol Laryngol Suppl, 181(3-13.

[63] Lopez I, Ishiyama G, Tang Y, Tokita J, Baloh RW, Ishiyama A (2005). Regional estimates of hair cells and supporting cells in the human crista ampullaris. J Neurosci Res, 82(3): 421-431.

[64] Gopen Q, Lopez I, Ishiyama G, Baloh RW, Ishiyama A (2003). Unbiased stereologic type I and type II hair cell counts in human utricular macula. Laryngoscope, 113(7): 1132-1138.

[65] Shiga A, Nakagawa T, Nakayama M, Endo T, Iguchi F, Kim TS, Naito Y, Ito J (2005). Aging effects on vestibulo-ocular responses in C57BL/6 mice: comparison with alteration in auditory function. Audiol Neurootol, 10(2): 97-104.
[66] Yamasoba T, Lin FR, Someya S, Kashio A, Sakamoto T, Kondo K (2013). Current concepts in age-related hearing loss: Epidemiology and mechanistic pathways. Hear Res, 303(30-38.

[67] Ohlemiller KK (2009). Mechanisms and genes in human strial presbycusis from animal models. Brain Res, 1277(70-83.

[68] Schuknecht HF (1955). Presbycusis. Laryngoscope, 65(6): 402-419.

[69] Cheng AG, Cunningham LL, Rubel EW (2005). Mechanisms of hair cell death and protection. Curr Opin Otolaryngol Head Neck Surg, 13(6): 343-348.

[70] Someya S, Yamasoba T, Kujoth GC, Pugh TD, Weindruch R, Tanokura M, Prolla TA (2008). The role of mtDNA mutations in the pathogenesis of age-related hearing loss in mice carrying a mutator DNA polymerase gamma. Neurobiol Aging, 29(7): 1080-1092.

[71] Someya S, Xu J, Kondo K, Ding D, Salvi RJ, Yamasoba T, Rabinovitch PS, Weindruch R, Leeuwenburgh C, Tanokura M, Prolla TA (2009). Age-related hearing loss in $\mathrm{C} 57 \mathrm{BL} / 6 \mathrm{~J}$ mice is mediated by Bak-dependent mitochondrial apoptosis. Proc Natl Acad Sci U S A, 106(46): 19432-19437.

[72] Uchida Y, Sugiura S, Ando F, Nakashima T, Shimokata H (2011). Molecular genetic epidemiology of age-related hearing impairment. Auris Nasus Larynx, 38(6): 657-665.

[73] Le Prell CG, Yamashita D, Minami SB, Yamasoba T, Miller JM (2007). Mechanisms of noise-induced hearing loss indicate multiple methods of prevention. Hear Res, 226(1-2): 22-43.

[74] Cawthorne T (1946). Vestibular injuries. Proc R Soc Lond B Biol Sci, 39(270-273.

[75] Yardley L, Beech S, Zander L, Evans T, Weinman J (1998). A randomized controlled trial of exercise therapy for dizziness and vertigo in primary care. Br J Gen Pract, 48(429): 1136-1140.

[76] Alrwaily M, Whitney SL (2011). Vestibular rehabilitation of older adults with dizziness. Otolaryngol Clin North Am, 44(2): 473-496, x.

[77] Whitney SL, Wrisley DM, Marchetti GF, Furman JM (2002). The effect of age on vestibular rehabilitation outcomes. Laryngoscope, 112(10): 1785-1790.

[78] Yardley L, Barker F, Muller I, Turner D, Kirby S, Mullee M, Morris A, Little P (2012). Clinical and cost effectiveness of booklet based vestibular rehabilitation for chronic dizziness in primary care: single blind, parallel group, pragmatic, randomised controlled trial. BMJ, 344(e2237. 
[79] Yardley L, Donovan-Hall M, Smith HE, Walsh BM, Mullee M, Bronstein AM (2004). Effectiveness of primary care-based vestibular rehabilitation for chronic dizziness. Ann Intern Med, 141(8): 598-605.

[80] Wall C, 3rd (2010). Application of vibrotactile feedback of body motion to improve rehabilitation in individuals with imbalance. J Neurol Phys Ther, 34(2): 98-104.

[81] Wall C, 3rd, Kentala E (2005). Control of sway using vibrotactile feedback of body tilt in patients with moderate and severe postural control deficits. J Vestib Res, 15(5-6): 313-325.

[82] Vuillerme N, Cuisinier R (2009). Sensory supplementation through tongue electrotactile stimulation to preserve head stabilization in space in the absence of vision. Invest Ophthalmol Vis Sci, 50(1): 476-481.

[83] Priplata AA, Niemi JB, Harry JD, Lipsitz LA, Collins JJ (2003). Vibrating insoles and balance control in elderly people. Lancet, 362(9390): 11231124 .

[84] Someya S, Yu W, Hallows WC, Xu J, Vann JM, Leeuwenburgh C, Tanokura M, Denu JM, Prolla TA (2010). Sirt3 mediates reduction of oxidative damage and prevention of age-related hearing loss under caloric restriction. Cell, 143(5): 802-812. 